Article

\title{
Structure and Physicochemical Properties of Water Treated under Nitrogen with Low-Temperature Glow Plasma
}

\author{
Jarosław Chwastowski ${ }^{1}$, Katarzyna Ciesielska ${ }^{2}$, Wojciech Ciesielski ${ }^{2}$, Karen Khachatryan ${ }^{3} \mathbb{}{ }^{10}$, \\ Henryk Kołoczek ${ }^{1}$, Damian Kulawik ${ }^{2}$, Zdzisław Oszczęda ${ }^{4}$, Piotr Tomasik ${ }^{4}$ * and \\ Mariusz Witczak ${ }^{3}$ (D) \\ 1 Institute of Chemistry and Inorganic Technology, Krakow University of Technology, Warszawska Str. 24, \\ 31155 Krakow, Poland; jchwastowski@chemia.pk.edu.pl (J.C.); koloczek@indy.chemia.pk.edu.pl (H.K.) \\ 2 Institute of Chemistry, Jan Dlugosz University, Armii Krajowej Ave. 13-15, 42201 Częstochowa, Poland; \\ k.ciesielska@ujd.edu.pl (K.C.); w.ciesielski@interia.pl (W.C.); d.kulawik@ujd.edu.pl (D.K.) \\ 3 Faculty of Food Technology, University of Agriculture in Krakow, Balicka Str. 122, 30149 Krakow, Poland; \\ rrchacza@cyf-kr.edu.pl (K.K.); mariusz.witczak@urk.edu.pl (M.W.) \\ 4 Nantes Nanotechnological Systems, Dolnych Młynów Str. 24, 59700 Bolesławiec, Poland; \\ oszczeda@stomadent.pl \\ * Correspondence: rrtomasi@cyf-kr.edu.pl
}

Received: 23 March 2020; Accepted: 1 May 2020; Published: 7 May 2020

check for updates

\begin{abstract}
Water treated with low-temperature, low-pressure glow plasma (GP) in contact with air stimulates various microorganisms, the growth of various plants and provides healthy breeding of various animals. In this paper, we present water treated with GP under oxygen-free nitrogen. It is potentially suitable for breeding anaerobic microorganisms, and increasing the crops of plants utilizing atmospheric nitrogen. Deionized water saturated with oxygen-free nitrogen was treated for 5 to 90 min with low-temperature glow plasma (GP). That operation produced nitrogen in various exited states depending on the treatment time. These excited nitrogen molecules built aqueous clathrates around them. The number and structure of those clathrates depended on the time of the treatment with GP. In terms of mass, density, $\mathrm{pH}$, conductivity, surface tension, Ultraviolet-Visible (UV-VIS), Fourier Transformation Infrared (FTIR), Raman and Electron Spin Resonance (ESR) spectra as well as Differential Scanning Calorimetry (DSC), the macrostructure of water saturated with nitrogen treated with GP strongly depended on the treatment time. Based on the entropy criterion, the macrostructure formed on 30 and 5 min treatment was the most and least organized, respectively.
\end{abstract}

Keywords: clathrate hydrates; FTIR; glow plasma; nitrogen excited states; water stretching modes

\section{Introduction}

In a macrosystem, water molecules form a hydrogen-bonded network with localized and structured clusters. They can arrange into different structures of water, e.g., small ones of four molecules, which may then group into relatively stable octamers. The water molecules also develop much larger water clusters capable of interlinking and translating throughout space. Such clusters dynamically form both open low density and condensed network [1]. The clusters of water can interconvert between lower and higher structures. The presence of dissolved gases and other solutes and temperature affect the equilibrium between these structures influencing the properties of water [2].

There are several methods of physical and physicochemical modifications of the water macrostructure [3]. Among them, modifications with plasma are listed. They involve plasma generated with a variety of methods and various modes of their application. Thus, an abundant 
number of papers [4-17] describe procedures in which plasma was generated by electric static or pulsed either dc low-voltage or RF discharges inside gas bubbles formed in water. Such treatment produced ozone [8] and hydrogen peroxide [11,13,18,19]. It could also evoke reactions of various organic compounds $[20,21]$. Oxidative properties of plasma treated water vapor was used for the oxidation of thin titanium films [22]. Since plasma treated water appeared a superior electrolyte, it was applied as anodizing electrolyte for production of nanoporous $\mathrm{TiO}_{2}$ nanotubes [23].

In our recent paper [24] structure and physicochemical properties of water treated with low-temperature, low-pressure glow plasma (GP) in the air was presented. Under fixed parameters of the GP generation, the structure and physicochemical properties of resulting water depended on the time of the GP treatment. It should be mentioned that there is an abundant literature on low-temperature glow plasma. In contrast to corresponding sources (see [25-27] and references therein) referring to atmospheric pressure cold plasma, low-pressure plasma was used in our studies.

On such treatment, macrostructure of water was declusterized and, simultaneously, molecules of triplet oxygen dissolved in the water were excited into the singlet state. The latter molecules were stabilized by declusterized water molecules which built aqueous clathrates with the singlet oxygen molecules inside. GP applied in our recent [24] and present studies was distinctly distinguished from plasmas mentioned above. In contrast to other types of plasma, GP generated neither ozone nor hydrogen peroxide and it could not evoke any oxidation of aldehydes or alcohols.

Benefits resulting from the use of that water were shown in a series of subsequent papers. Thus, it was demonstrated that water stimulated growth and pathogenicity of entomopathogenic fungi used as biopesticides [28]. Murawski et al. described benefits of cryopreservation of ram [29] and boar [30] semen in GP-treated water. The barley malt quality could be improved when GP-treated water was applied [31]. Watering peppermint with GP-treated water provided fascinating results [32]. Although such watering had no essential effect on the yield of the essential oil and plant crop yield, the composition of the essential oil dramatically changed. The menthol content in it was distinctly lower and, simultaneously, the bactericidal properties of that oil increased. Several new components of that oil could be characterized. Bioaccumulation of cations and anions in leaves, stems and roots also changed.

Several interesting applications of water treated with GP in contact with the air are presented in a review [33] newly published monograph [34]. These applications presented based on unpublished research reports deal with the plant cultivation and animal breeding.

These results prompted us to use GP for the water treatment under oxygen-free atmosphere of nitrogen. Deionized water was saturated with rigorously oxygen-free nitrogen then treated under such nitrogen for 0 (control sample), 5, 15, 30, 60 and 90 min. Physicochemical properties of resulting samples were characterized based on estimations of $\mathrm{pH}$, conductivity, surface tension, differential scanning calorimetry (DSC), density and all Fourier Transformation Infrared (FTIR), and Electron Spin Resonance (ESR), Ultraviolet-Visible (UVVIS) and Raman spectra. Comparison of results of those measurements with relevant data for water treated with GP in the air gave clear evidence that both types of water were entirely different.

\section{Materials and Methods}

\subsection{Preparation of GP-Treated Water (GPTW)}

Through the deionized water a stream of nitrogen was bubbled for $15 \mathrm{~min}$. Its flow rate depended on the volume of the water sample. In case of the $200 \mathrm{~mL}$ sample it was $10 \mathrm{~mL} / \mathrm{min}$ ). Nitrogen was deoxygenated by passing through an absorber filled with an alkaline solution of resorcinol. That water (200 mL) was placed in $250 \mathrm{~mL}$ glass bottles and free space over the liquid was additionally filled with deoxygenated nitrogen. The whole was placed in the chamber of the reactor [35] (Figure 1) and exposed to GP for 5, 15, 30, 60 and $90 \mathrm{~min}$. Plasma of $38^{\circ} \mathrm{C}$ was generated at $5 \times 10^{-3} \mathrm{mbar}, 800 \mathrm{~V}, 50$ 
$\mathrm{mA}$ and $10 \mathrm{KHz}$ frequency using a lamp patented by Oszczeda [36]. The produced water was stored at ambient temperature in $100 \mathrm{~mL}$ closed teflon containers.

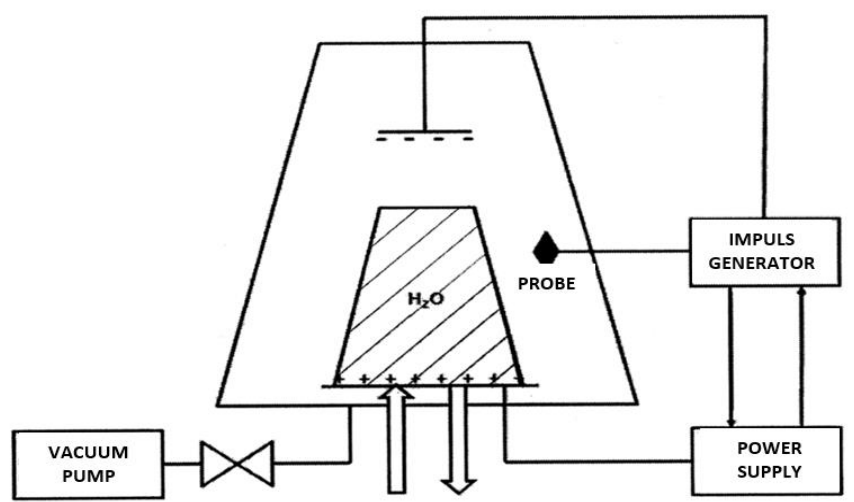

Figure 1. Scheme of the glow plasma (GP) generator and the mode of the treating water with it [35].

\subsection{Physicochemical Studies of GPTW}

\subsection{1. $\mathrm{pH}$}

The measurements for all samples (both control samples and these treated with GP for 5 to $90 \mathrm{~min}$ ) were performed at $25^{\circ} \mathrm{C}$ in triplicates with a laboratory multifunction meter CP-501 (Elmetron, Zabrze, Poland) equipped with glass electrode HYDROMET, Type ERH-11.

\subsubsection{Conductivity}

Estimations were performed at $25{ }^{\circ} \mathrm{C}$ with an ELMETRON CPC-505 instrument (Zabrze, Poland) equipped in an ELMETRON EC-60 sensor. The estimations were taken in triplicates for both control samples and these treated with GP for 5 to $90 \mathrm{~min}$.

\subsubsection{Surface Tension}

The surface tension was measured with the du Nouy'a ring technique using an STA-1 tensiometer (Sinterface, Berlin, Germany) equipped in a ring of the 9.55 radius. The normal speed of the ring was applied. The measurements were performed at $24 \pm 0.5^{\circ} \mathrm{C}$ for $1 \mathrm{~g} / \mathrm{L}$ samples of $0.997 \mathrm{~g} / \mathrm{L}$ density. The experiments were run in 7 replicates.

\subsubsection{Differential Scanning Calorimetry (DSC)}

Differential scanning calorimeter DSC 204F1 Phoenix (Netzsch, Germany) was used. Multipoint calibration ( $\mathrm{Hg}, \mathrm{In}, \mathrm{Sn}, \mathrm{Bi}, \mathrm{Zn}, \mathrm{CsCl})$ was involved. Analyzed samples (12 mg) were hermetically sealed in alumina capsules. The capsules were then punctured and cooled down to $-40{ }^{\circ} \mathrm{C}$ with the rate of $10^{\circ} \mathrm{C} / \mathrm{min}$ followed with heating to $140{ }^{\circ} \mathrm{C}$ with the same rate. Characteristic temperatures and enthalpy of transitions $\left(T_{\text {onset }}, T_{\text {mid }}, T_{\text {end }}\right.$ and $H$ ) were determined with Proteus Analysis (Netzsch, Germany) software. Experiments were duplicated.

\subsubsection{Water Density}

Water sample (12 L) was placed in NETZSCH 6.239.2-64.5.00 DSC crucibles and their weight determined with precision of $10^{-6} \mathrm{~g}$ at $22^{\circ} \mathrm{C}$ using a Mettler-Toledo (Greifensee, Switzerland) XPR56 balance. Density $(\mathrm{d})$ was calculated from Equation $\mathrm{d}=\mathrm{m} / \mathrm{V}$ where $\mathrm{m}$ and $\mathrm{V}$ are weight and volume of the sample, respectively. 


\subsubsection{FTIR-ATR (Fourier Transformation Infrared-Attenuated Total Reflectance) Spectra}

The FTIR-ATR spectra of the film were recorded following the method formerly described [23]. Thus, the measurements were performed in the range of $4000-700 \mathrm{~cm}^{-1}$ at resolution of $4 \mathrm{~cm}^{-1} \mathrm{using}^{\mathrm{a}}$ Mattson 3000 FT-IR (Madison, Wisconsin, USA) spectrophotometer. That instrument was equipped with a $30 \mathrm{SPEC} 30^{\circ}$ reflectance adapter fitted with the MIRacle ATR accessory from PIKE Technologies Inc., Madison, Wisconsin, USA.

\subsubsection{ESR (Electron Spin Resonance) Spectra}

The spectra were recorded at room temperature employing an instrument constructed at Wroclaw Technical University. The range of the X-band $(\mathrm{v}=9.5 \mathrm{GHz}, \lambda=3.2 \mathrm{~cm}$ ) was employed at the 20-25 $\mathrm{dB}$ attenuation and $2048 \mathrm{~s}$ swiping time. An EPR controller software designed for taking the EPR spectra was applied. For samples saturated with nitrogen $\mathrm{g} \approx 2.16$.

\subsubsection{UV/VIS (Ultraviolet/Visible) Absorption Spectra}

The spectra were recorded with a Thermo Scientific Evolution 220 (Thermo Fischer Scientific, Waltham, MA, USA) spectrophotometer in the wavelength range of 190-1100 nm in a quartz cell of $10 \mathrm{~mm}$ path length as formerly described in our recent paper [24]. The instrument was set on automatic measuring mode at medium scan speed and $1.0 \mathrm{~nm}$ slit width.

\subsubsection{Raman Spectra}

The spectra were taken with a Perkin-Elmer MPF44A Fluorescence Spectrophotometer equipped with a xenon lamp (excitation at $360 \mathrm{~nm}$ ) and $4 \mathrm{~mL}$ quartz cell following the method described in [23]. The spectra were recorded for:

- Control distilled water stored in contact with the air,

- Control distilled water saturated with deoxygenated nitrogen

- $\quad$ Distilled water saturated with deoxygenated nitrogen exposed to GP for 5, 15, 30, 60 and 90 min.

\section{Results and Discussion}

Performed studies delivered clear evidence for deep changes evoked by GP in the water macrostructure. The plasma used in this study was generated by a lamp with the current of 10 $\mathrm{kHz}$ frequency. Nevertheless, changes in the GPTW macrostructure pointed to the intervention from the waves of $\mathrm{GHz}$ and possibly $\mathrm{MHz}$ frequency. Likely, the initial frequency was multiplied accordingly as a result of so-called electromagnetic interference [37].

In the UV-absorption spectra (Figure 2) of control water containing dissolved air a shoulder of a main intensive band at $195 \mathrm{~nm}$ could be distinguished at approximately $230 \mathrm{~nm}$. It resulted from ${ }^{1} \mathrm{~A}_{1} \rightarrow{ }^{1} \mathrm{~B}_{1}$ transition [3]. Its intensity was 0.225 a.u. That shoulder was followed by a weak $(0.020$ a.u. $)$ maximum at $739 \mathrm{~nm}$ common in such spectrum of water [38]. Saturation of the water with nitrogen resulted in considerable decrease in absorbance of the shoulder to 0.151 a.u. leaving the intensity of the maximum at $739 \mathrm{~nm}$ intact. The spectrum represented solely the spectrum of water as the bands of molecular nitrogen could be observed in the region of 80-100 $\mathrm{nm}$ [39]. Thus, the decrease in the intensity of the shoulder could be related to decreased in the number of water molecules with lone electron pairs not engaged in the hydrogen bonding, that is, those providing the $n \rightarrow \pi^{*}$ transitions.

According to the Roentgen hypothesis, in liquid water ice-like structures involving intermolecular hydrogen bonds coexisted with isolated $\mathrm{H}_{2} \mathrm{O}$ monomers [40]. One should keep in mind that control water, $\mathrm{W}$, used in our studies contained dissolved oxygen as well as $\mathrm{CO}_{2}$, as evidenced by $\mathrm{pH}$ of that water (Table 1). That water had $\mathrm{pH}$ 5.95. Both these solutes produced a certain disorder in the macrostructure of the water. Saturating that water with nitrogen brought $\mathrm{pH}$ of that water to 6.68 showing that some residual $\mathrm{CO}_{2}$ could still remain in the solution. However, first of all, the number 
of molecules producing disorder of the macrostructure was essentially reduced as at $20{ }^{\circ} \mathrm{C}$ water dissolves $0.0425 \mathrm{~g} / \mathrm{kg}$ oxygen and only $0.0185 \mathrm{~g} / \mathrm{kg}$ nitrogen [41].

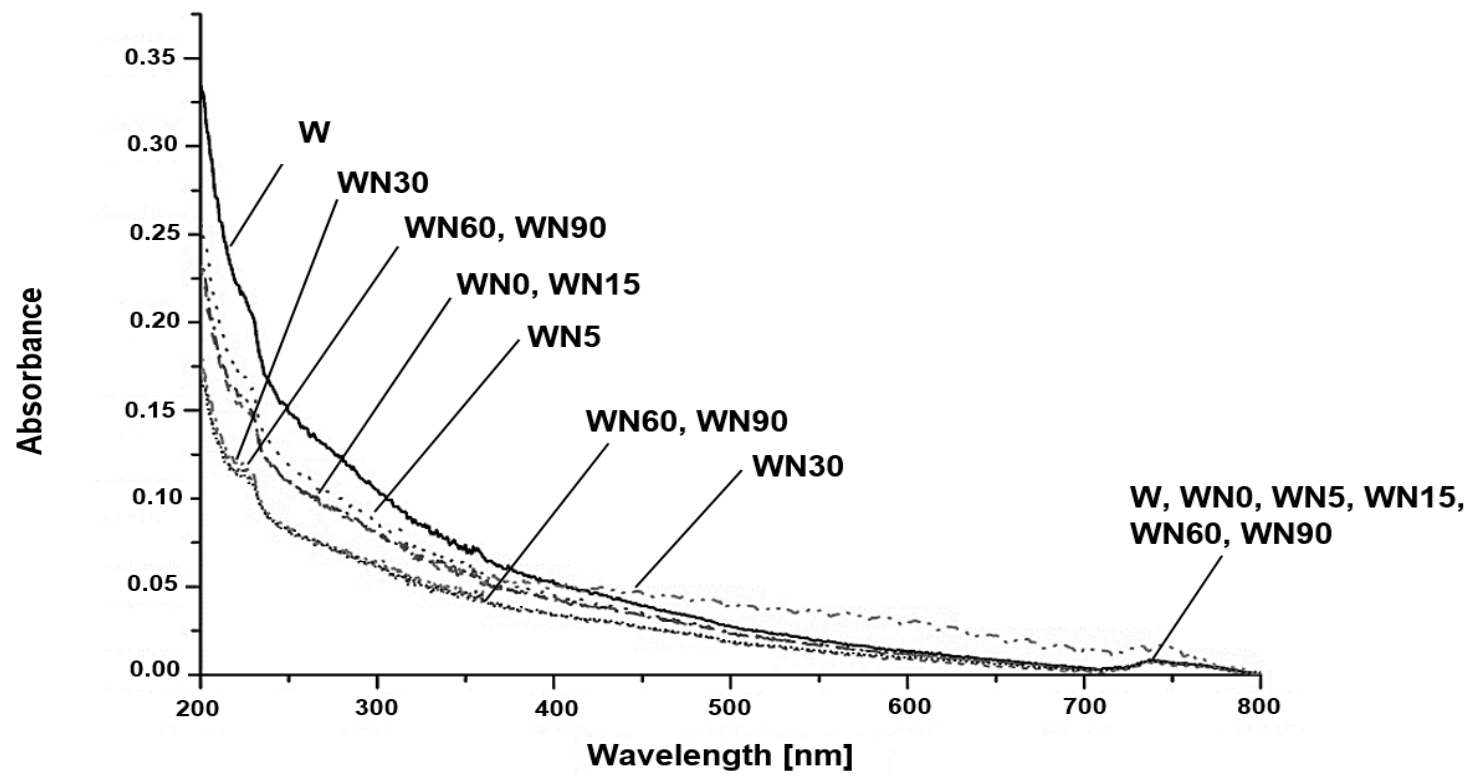

Figure 2. Ultraviolet (UV) absorption spectra of controlled, deionized water maintained in the air (W) and controlled deionized water washed with nitrogen (WN0), and that latter water after the GP treatment for 5 to $90 \mathrm{~min}$ (WN5-WN90), respectively.

Table 1. Selected physicochemical properties of control waters and water treated with GP under nitrogen.

\begin{tabular}{cccccc}
\hline Water $^{\mathbf{a}}$ & $\begin{array}{c}\text { Mass } \\
(\mathbf{m g})\end{array}$ & $\begin{array}{c}\text { Density } \\
\left(\mathbf{g} / \mathbf{c m}^{\mathbf{3}} \mathbf{b}\right.\end{array}$ & $\mathbf{p H}$ & $\begin{array}{c}\text { Conductivity } \\
(\boldsymbol{\mu S} / \mathbf{c m})\end{array}$ & $\begin{array}{c}\text { Surface Tension } \\
(\mathbf{m N} / \mathbf{m})\end{array}$ \\
\hline W & $11.95 \pm 0.15$ & 0.995833 & 5.95 & $3.103 \pm 0.008$ & $64.99 \pm 0.30$ \\
WN0 & $11.80 \pm 0.20$ & 0.983333 & 6.68 & $2.353 \pm 0.007$ & $68.28 \pm 0.39$ \\
WN5 & $12.95 \pm 0.15$ & 1.079167 & 6.72 & $2.220 \pm 0.010$ & $69.22 \pm 0.32$ \\
WN15 & $11.90 \pm 0.30$ & 0.991667 & 6.68 & $2.647 \pm 0.007$ & $61.91 \pm 0.22$ \\
WN30 & $12.15 \pm 0.05$ & 1.012500 & 6.57 & $2.343 \pm 0.007$ & $67.46 \pm 0.25$ \\
WN60 & $11.30 \pm 0.10$ & 0.950000 & 6.62 & $2.483 \pm 0.006$ & $59.91 \pm 0.61$ \\
WN90 & $12.00 \pm 0.25$ & 0.979167 & 6.59 & $2.430 \pm 0.010$ & $61.73 \pm 0.18$
\end{tabular}

\footnotetext{
a $\mathrm{W}$-deionized water stored in contact with the air, WN0-deionized water saturated with nitrogen, prior to treatment with GP, WN5-WN90 deionized water treated with GP for 5 to $90 \mathrm{~min}$, respectively. ${ }^{\mathrm{b}}$ The precision of estimation did not exceed $\pm 0.000007 \mathrm{~g} / \mathrm{cm}^{3}$.
}

WN5 and WN30 water seemed to have a particular macrostructures, as evidenced by their mass, density, conductivity and surface tension (Table 1). Both samples exhibited the highest mass and density, the lowest conductivity and the highest surface tension among all prepared GP-treated water samples.

The absorbance of the shoulder at $230 \mathrm{~nm}$ in the spectrum of the water saturated with nitrogen, WN0, increased on treating with GP for 5 to $15 \mathrm{~min}$. Thus, a disorder of the macrostructure of that water increased. Prolonged GP treatment ordered the macrostructure as it could be deduced from reduction of the absorbance of that shoulder below that in the spectrum of WNO. The $5 \mathrm{~min}$ GP treatment of WN0 most efficiently increased the absorbance of the shoulder but extending such treatment to $15 \mathrm{~min}$ reduced its intensity to that in the spectrum of non-treated water. In consequence, both spectra were like one another. The GP treatment for $30 \mathrm{~min}$ produced some essential change of the spectrum. The absorbance of that spectrum was initially quite low but at approximately $360 \mathrm{~nm}$ a jump of the spectral line was observed and, as a consequence, the intensity of the spectral line became much higher than the intensity of the remaining spectra (Figure 2). The spectra of the water GP-treated for 60 and $90 \mathrm{~min}$ 
were identical and their absorbance was the lowest among all measured spectra (Figure 2). Thus, treating WN0 with GP for 30-90 min organized its macrostructure.

FTIR spectra (Figure 3) of water in the range of 4000-1250 $\mathrm{cm}^{-1}$ consisted of two $\mathrm{OH}$ bands (stretching modes of the hydroxyl group) combined in one broad peak and $\mathrm{OH}$ (bending modes in the hydroxyl group) bands. The band situated at $3243 \mathrm{~cm}^{-1}$ is, in fact, composed of two bands reflecting asymmetric (longer wavelength) and symmetric (shorter wavelength) vibrations in the water molecule [3]. They could be recognized after the Gaussian distribution of that band. One might see that positions of all three bands were insensitive to the treatment with plasma, and the intensity of those bands subtly depended on it (see Table 2).

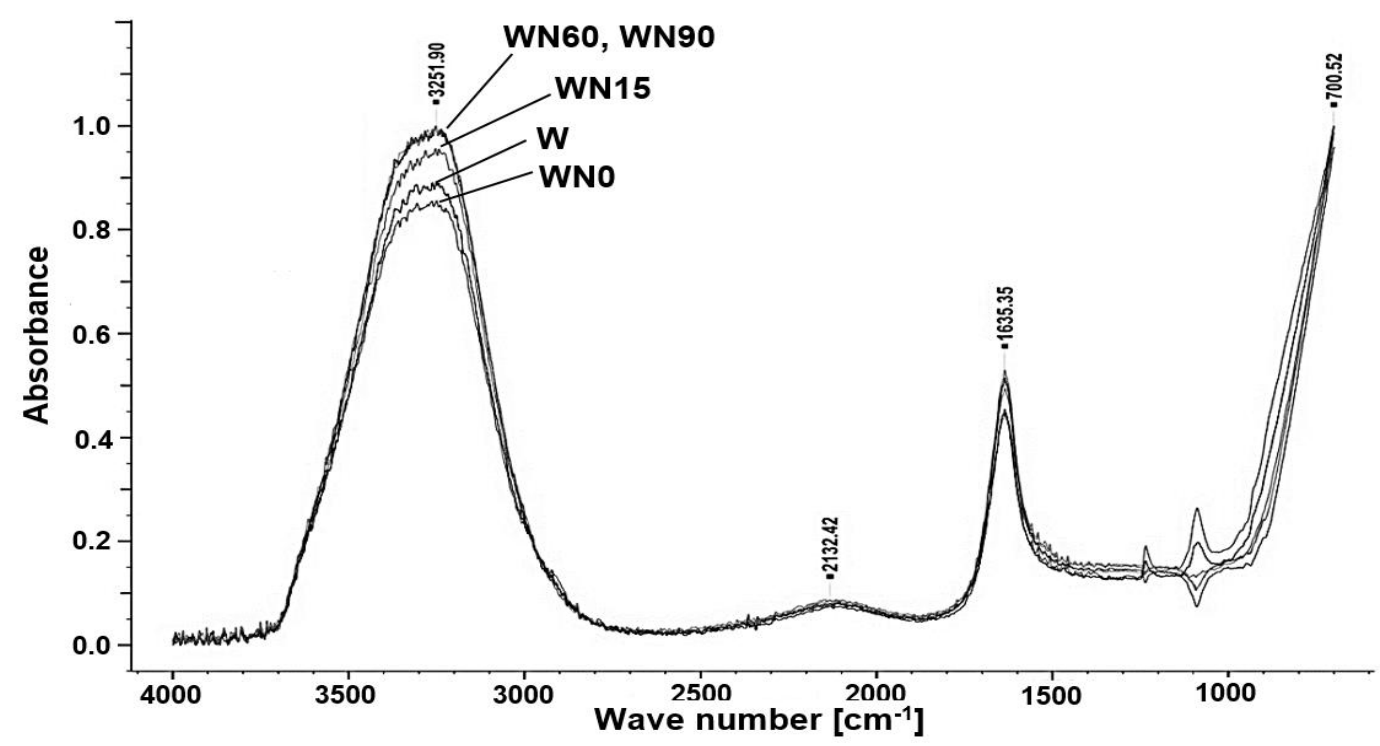

Figure 3. Fourier Transformation Infrared (FTIR) spectra of deionized water stored in contact with the air (W) and saturated with nitrogen prior (WNO) and after treating with GP for 5 to $90 \mathrm{~min}$ (WN5-WN90), respectively.

Table 2. Intensity of the $\mathrm{OH}$ stretching (bands $\mathrm{A}$ and $\mathrm{B}^{\mathrm{a}}$ ) and bending (band $\mathrm{C}$ ) modes in the FTIR spectra of water taken in the region of $4000-1500 \mathrm{~cm}^{-1}$.

\begin{tabular}{|c|c|c|c|c|c|c|}
\hline \multirow{2}{*}{ Sample ${ }^{b}$} & \multicolumn{3}{|c|}{ Band Intensity } & \multicolumn{3}{|c|}{ Intensity Ratio } \\
\hline & A $\left(3494 \mathrm{~cm}^{-1}\right)$ & B $\left(3265 \mathrm{~cm}^{-1}\right)$ & $C\left(1633 \mathrm{~cm}^{-1}\right)$ & A/B & $\mathrm{A} / \mathrm{C}$ & $\mathrm{B} / \mathrm{C}$ \\
\hline W & 0.0642 & 0.3266 & 0.1633 & 0.197 & 0.393 & 2.000 \\
\hline WN0 & 0.0810 & 0.3403 & 0.1732 & 0.238 & 0.468 & 1.965 \\
\hline WN5 & 0.0711 & 0.3305 & 0.1693 & 0.215 & 0.420 & 1.952 \\
\hline WN15 & 0.0721 & 0.3323 & 0.1693 & 0.217 & 0.426 & 1.963 \\
\hline WN30 & 0.0681 & 0.3294 & 0.1693 & 0.207 & 0.402 & 1.946 \\
\hline WN60 & 0.0730 & 0.3315 & 0.1703 & 0.220 & 0.429 & 1.947 \\
\hline WN90 & 0.0780 & 0.3333 & 0.1703 & 0.234 & 0.458 & 1.957 \\
\hline
\end{tabular}

Saturation of the water containing dissolved air with oxygen free nitrogen increased the deal of asymmetric stretching modes of the water. It was manifested by the changes of the $\mathrm{A} / \mathrm{B}$ intensity ratio. Independently of the applied GP treatment time the deal of the water molecules with asymmetrically stretched $\mathrm{O}-\mathrm{H}$ bonds declined although that decline was irregular against the GP treatment time. Prolonged treatment recovered, to a certain extent, asymmetrically vibrating molecules. The presence of nitrogen resulted in some, irregular against the treatment time, increase in the intensity of the B and $\mathrm{C}$ bands. Such behavior differed from that of the water containing dissolved air. The latter water contained the highest number of asymmetrically vibrating molecules after the 5 min GP treatment [24]. 
Raman spectra taken with an instrument equipped in a xenon lamp offered the most convincing evidence for the changes of the macrostructure of water induced by the treating water with GP (Figure 4). The spectrum of control, deionized water maintained in the air, $\mathrm{W}$, consisted of fairly intensive, clearly complex band centered at $365 \mathrm{~nm}$ followed by a shoulder and another, less intensive band at $372 \mathrm{~nm}$. That band had at least two shoulders on its long wavelength side. Saturation of deionized water with oxygen-free nitrogen, WN0, essentially changed the spectral pattern. The weaker non-symmetric band at $370 \mathrm{~nm}$ was preceded by at least two shoulders and followed by a fairly intensive band at $377 \mathrm{~nm}$. That band exhibited a weak shoulder on its long wavelength side. The treating the latter water with GP for $5 \mathrm{~min}$, WN5, drastically changed the spectral pattern. A very strong complex band with shoulders on its both sides developed at $373 \mathrm{~nm}$. In the region of 360-379 $\mathrm{nm}$, the spectrum of the water treated with GP for $15 \mathrm{~min}$, WN15, was identical with that of water treated with GP for $5 \mathrm{~min}$ but additional weak band appeared at $382 \mathrm{~nm}$. The character of the spectrum of water treated under nitrogen for $30 \mathrm{~min}$, WN30, resembled that taken for the water treated for $5 \mathrm{~min}$. There was a first complex weaker band at $368 \mathrm{~nm}$ followed by more intensive band at $376 \mathrm{~nm}$. The spectra of water treated under nitrogen for 60 (WN60) and 90 (WN90) min were considerably less intensive. They presented one complex broad band each with several shoulders. The spectrum of WN60 was more intensive than the spectrum of WN90. The maxima were centered at 375 and $371 \mathrm{~nm}$, respectively.

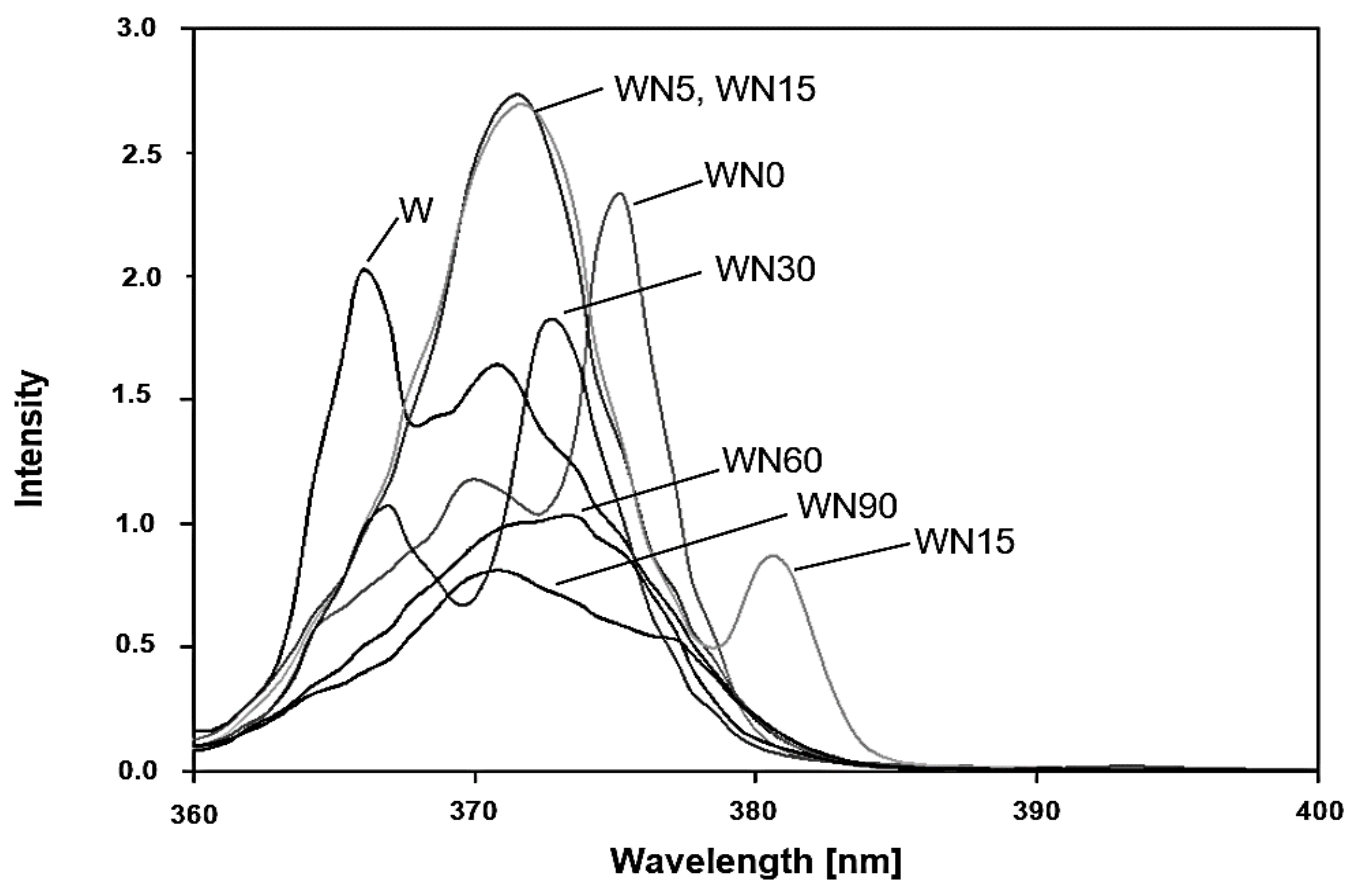

Figure 4. Raman spectra of deionized water stored in contact with the air (W) and saturated with nitrogen prior (WN0) and after treating with GP for 5 to $90 \mathrm{~min}$ (WN5-WN90), respectively.

Observed spectral changes were irregular against the GP treatment time suggesting building, for instance, aqueous clathrates of excited molecular nitrogen of varying excited states. The clathrates were formed of varying number of the guest molecules in aqueous cages built of different number of the water molecules. Such GP treatment time dependent irregularities were observed also in case of water GP-treated in the air [24].

Differential Scanning Calorimetry measurements delivered further information of the water macrostructure. The measurements were performed in the three-step regime, that is (i) freezing from room temperature to $-40{ }^{\circ} \mathrm{C}$, (ii) melting and (iii) heating to $+140{ }^{\circ} \mathrm{C}$. A typical graph is presented in Figure 5. The results are given in Table 3. 


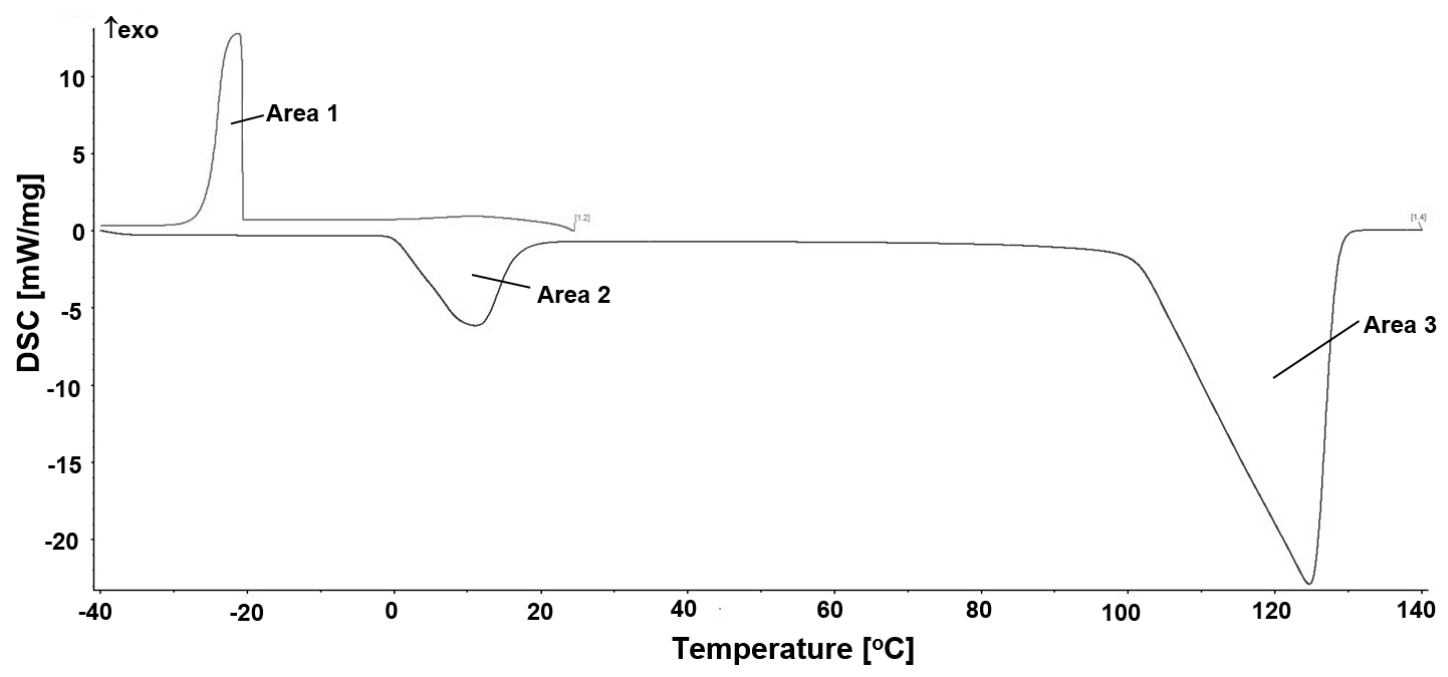

Figure 5. The typical course of the Differential Scanning Calorimetry (DSC) experiment shown for deionized water stored in the air.

Table 3. Results of the DSC measurements for water treated under nitrogen ${ }^{\text {a. }}$

\begin{tabular}{ccccccccccccc}
\hline \multirow{2}{*}{ Sample $^{\mathbf{b}}$} & \multicolumn{4}{c}{ Freezing } & \multicolumn{4}{c}{ Melting } & \multicolumn{4}{c}{ Evaporating } \\
\cline { 2 - 12 } & $\mathbf{T}_{\mathbf{1}}$ onset & $\mathbf{T}_{\mathbf{1}}$ mid & $\mathbf{T}_{\mathbf{1}}$ end & Area $_{\mathbf{1}}$ & $\mathbf{T}_{\mathbf{2}}$ onset & $\mathbf{T}_{\mathbf{2}}$ mid & $\mathbf{T}_{\mathbf{2}}$ end & Area $_{\mathbf{2}}$ & $\mathbf{T}_{\mathbf{3}}$ onset & $\mathbf{T}_{\mathbf{3}}$ mid & $\mathbf{T}_{\mathbf{3}}$ end & Area $_{\mathbf{3}}$ \\
\hline W & -20.6 & -21.5 & -25.4 & -281.1 & 0.1 & 11.0 & 16.8 & -355.9 & 100.9 & 125.0 & 128.8 & -2075.5 \\
WN0 & -20.6 & -21.4 & -25.0 & -284.2 & 0.1 & 10.9 & 16.1 & -361.2 & 101.0 & 124.2 & 128.0 & -2149.5 \\
WN5 & -19.4 & -20.3 & -24.1 & -297.0 & 0.2 & 11.0 & 16.2 & -373.9 & 101.1 & 124.9 & 128.9 & -2174.0 \\
WN15 & -18.4 & -19.1 & -23.9 & -303.4 & 0.2 & 10.2 & 15.7 & -379.0 & 101.1 & 123.9 & 127.6 & -2207.0 \\
WN30 & -20.7 & -21.3 & -24.8 & -294.0 & 0.1 & 10.5 & 16.1 & -374.6 & 100.7 & 124.0 & 127.8 & -2194.0 \\
WN60 & -20.7 & -21.4 & -24.5 & -304.8 & 0.1 & 10.1 & 15.0 & -385.2 & 101.1 & 123.2 & 127.0 & -2271.0 \\
WN90 & -19.2 & -19.9 & -23.4 & -303.3 & 0.1 & 10.5 & 15.3 & -379.8 & 100.9 & 123.3 & 127.0 & -2232.5 \\
\hline \multicolumn{4}{c}{}
\end{tabular}

Replacement of oxygen and carbon dioxide dissolved in control water, W, with nitrogen, WN0, had little effect upon temperature of phase transitions; however, their enthalpy considerably changed. Results of the GP treatment of water saturated with nitrogen depended upon the treatment time in an irregular manner, particularly in case of freezing. Except for $\mathrm{WN} 30$ and $\mathrm{WN} 60, \mathrm{~T}_{1}$ onset, $\mathrm{T}_{1}$ mid and $\mathrm{T}_{1}$ end parameters increased by approximately $1{ }^{\circ} \mathrm{C}$ in respect to these for WN0. Generally, the treatment with GP produced a small decrease in the temperature parameters for melting and freezing but data for WN5 and WN30 spoiled that relation. Areas of the phase transitions declined irregularly against the treatment time.

Entropy calculated from Equation (1) (see Table 4)

$$
\Delta \mathrm{S}=\Delta \mathrm{H} / \mathrm{T}
$$

declined by the treatment in the manner correlated with specific heat, $\mathrm{C}_{\mathrm{p}}$.

Thus, the treatment with GP changed the equilibrium between tetrahedral clathrates and ordered bulk structures. Nitrogen favored ordering of the macrostructure in respect to that in control water stored in the air probably, first of all, because of decreased content of disordering macrostructure solutes.

ESR spectra of water stored in the air exhibited a signal common for the presence of unpaired spins. They were ascribed to the triplet state of oxygen dissolved in that water. The signal ceased after the treatment of the water with GP and that fact was interpreted as the result of taking the excited singlet state [24]. In contrast to this, the ESR spectrum of the water saturated with nitrogen prior to its treatment with GP (W) did not exhibit any signal. After the treatment with GP, the ESR spectra of that water revealed a signals pattern that depended on the GP treatment time. 
Figure 6 presents ESR spectra of deionized water saturated with nitrogen after treating with GP for 5 to $90 \mathrm{~min}$. The time dependent pattern of the signals reflects a known complexity of the excitation of the nitrogen molecule $[42,43]$. This problem will be addressed in a separate paper.

Table 4. Thermodynamic data for treated with GP deionized water saturated with nitrogen.

\begin{tabular}{|c|c|c|c|c|c|c|}
\hline \multirow{2}{*}{ Sample ${ }^{a}$} & \multicolumn{2}{|c|}{$C_{p}$} & \multicolumn{2}{|c|}{$\Delta \mathbf{H}$} & \multicolumn{2}{|c|}{$\Delta \mathrm{S}$} \\
\hline & J/gK & $\mathrm{J} / \mathrm{molK}$ & $\mathrm{J} / \mathrm{g}$ & $\mathrm{J} / \mathrm{mol}$ & $\mathrm{J} / \mathrm{g} \mathrm{K}$ & $\mathrm{J} / \mathrm{molK}$ \\
\hline W & 0.363 & 0.026 & -2075.5 & -115.306 & 3.94362 & 0.219090 \\
\hline WN0 & 11.523 & 0.823 & -2149.5 & -119.417 & 3.95231 & 0.219573 \\
\hline WN5 & 13.254 & 0.947 & -2174.0 & -120.778 & 3.85214 & 0.214008 \\
\hline WN15 & 19.235 & 1.374 & -2207.0 & -122.611 & 3.52148 & 0.195638 \\
\hline WN30 & 37.235 & 2.659 & -2194.0 & -121.889 & 3.01258 & 0.167366 \\
\hline WN60 & 30.485 & 2.177 & -2271.0 & -126.167 & 3.25483 & 0.180824 \\
\hline WN90 & 25.237 & 1.802 & -2232.5 & -124.028 & 3.35684 & 0.186491 \\
\hline
\end{tabular}

These spectra demonstrated that depending on the treatment time differently built aqueous clathrates were generated with different excited state nitrogen molecules inside what was also documented in the corresponding Raman spectra (Figure 3).

In our former papers, following paper by Ramya and Venkanathan [44], formation of aqueous clathrates with singlet oxygen [24] as the guest molecules was postulated. It was suggested that molecular orbitals of those guests promoted the formation of the clathrates themselves and controlled their composition as well as their structure. Entropy values of the water treated with GP for varying time (Table 4), thus, containing various forms of excited nitrogen molecules, declined in the following order:

$$
\text { WN5 }>\text { WN15 }>\text { WN90 }>\text { WN60 }>\text { WN30 }
$$

That order suggested the stimulation of the formation of the clathrates and their stability dependent on the excited state of the nitrogen molecule. That order roughly correlated with the order of declining absorbance of the shoulder at $230 \mathrm{~nm}$ in the UV absorption spectra of those waters (Figure 1), that is, with declining number of non-engaged lone electron pairs. It was equivalent to increasing ordering of the water macrostructure.

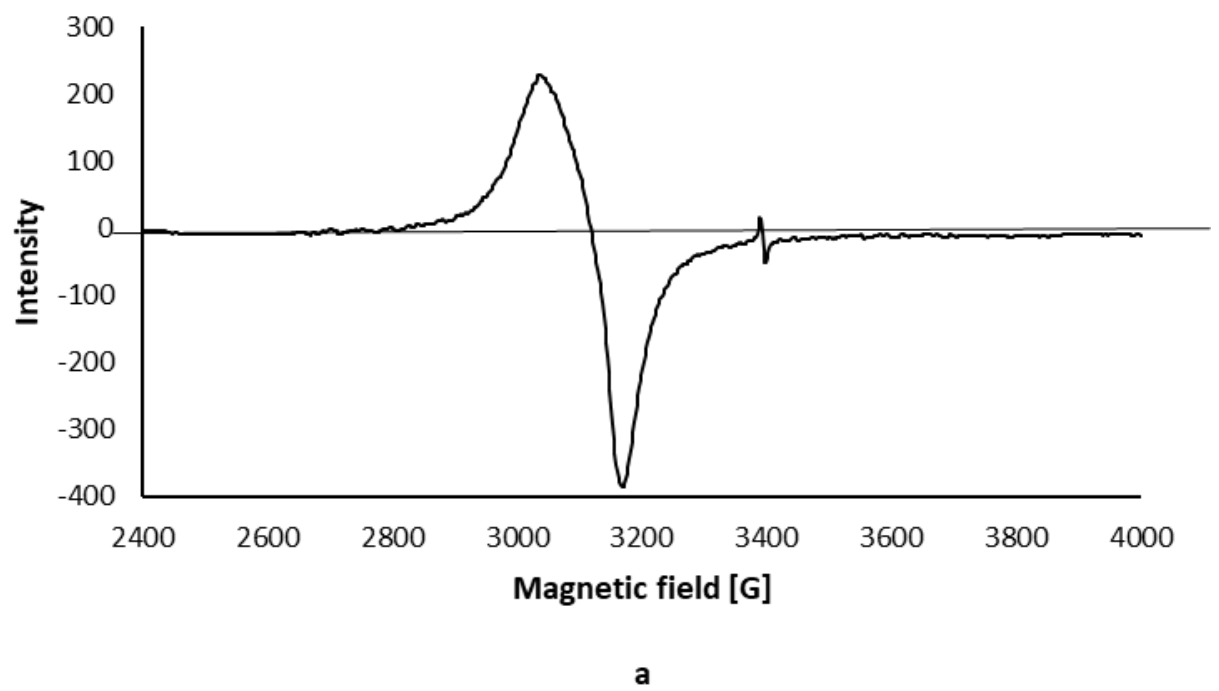

Figure 6. Cont. 


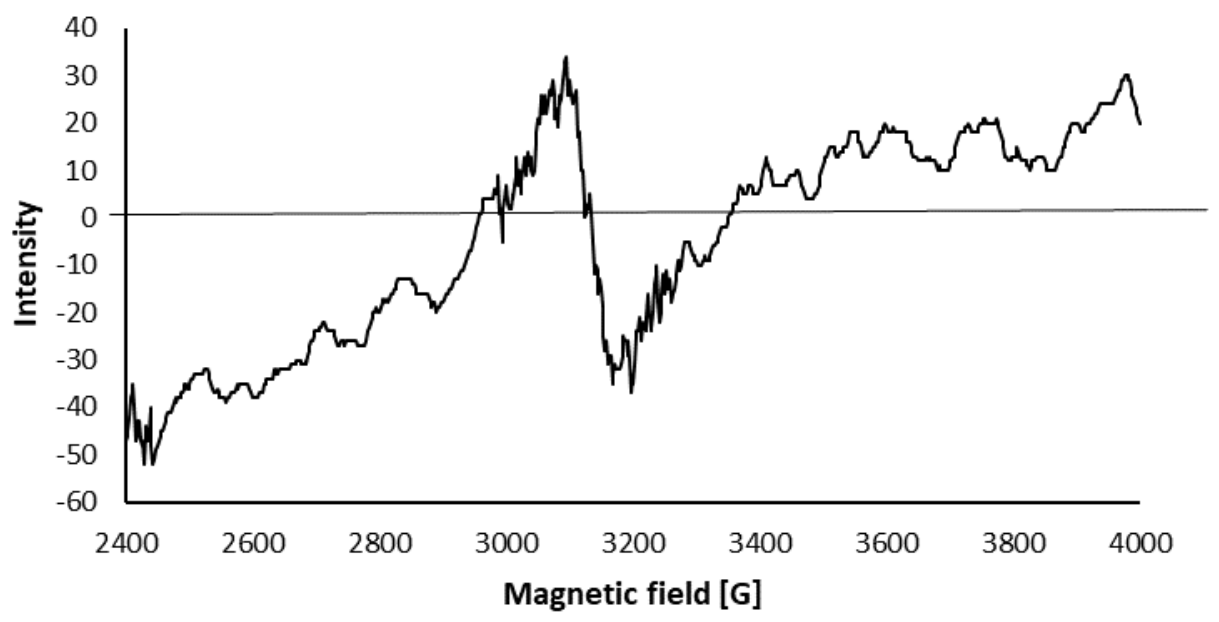

b
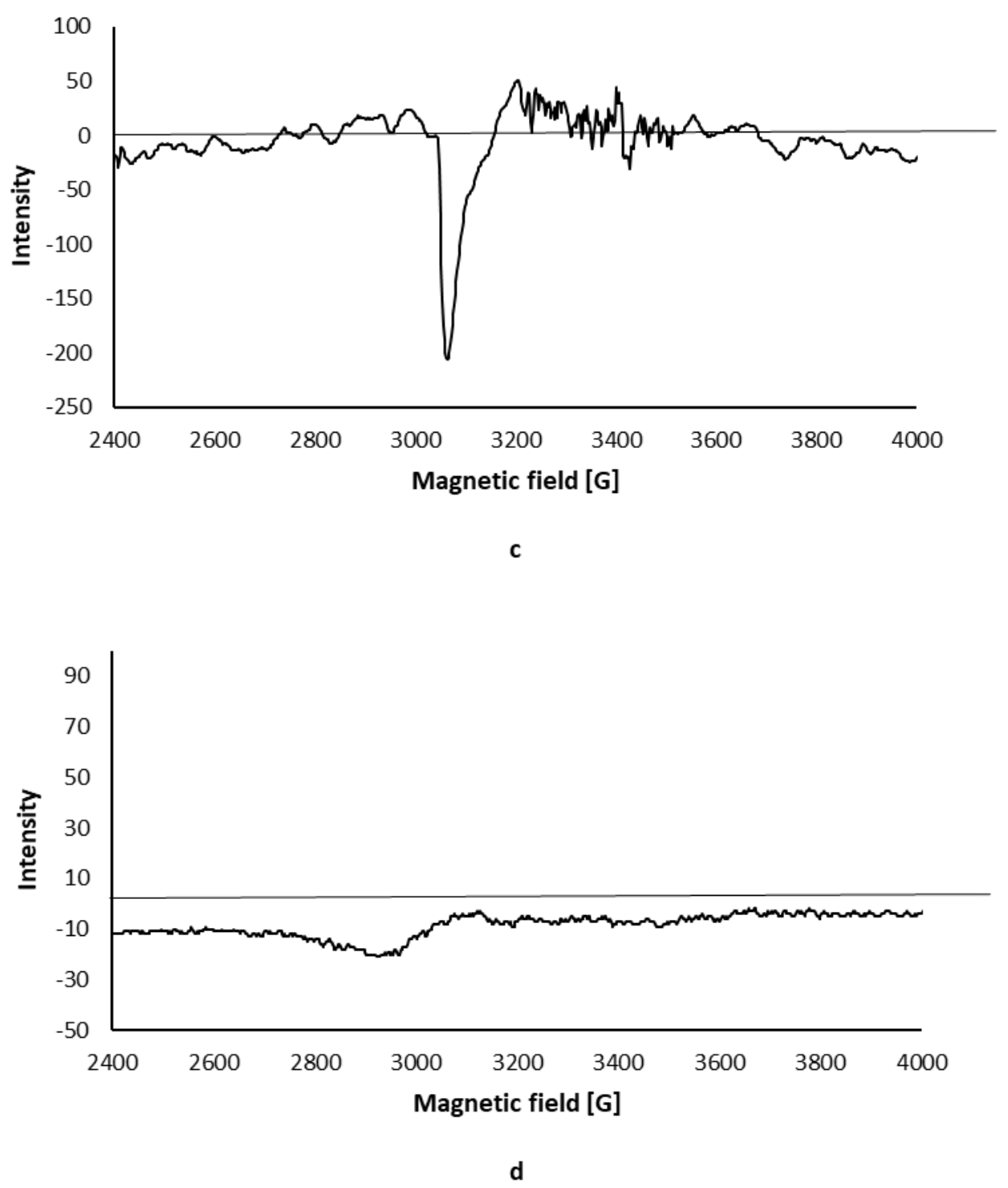

Figure 6. Cont. 


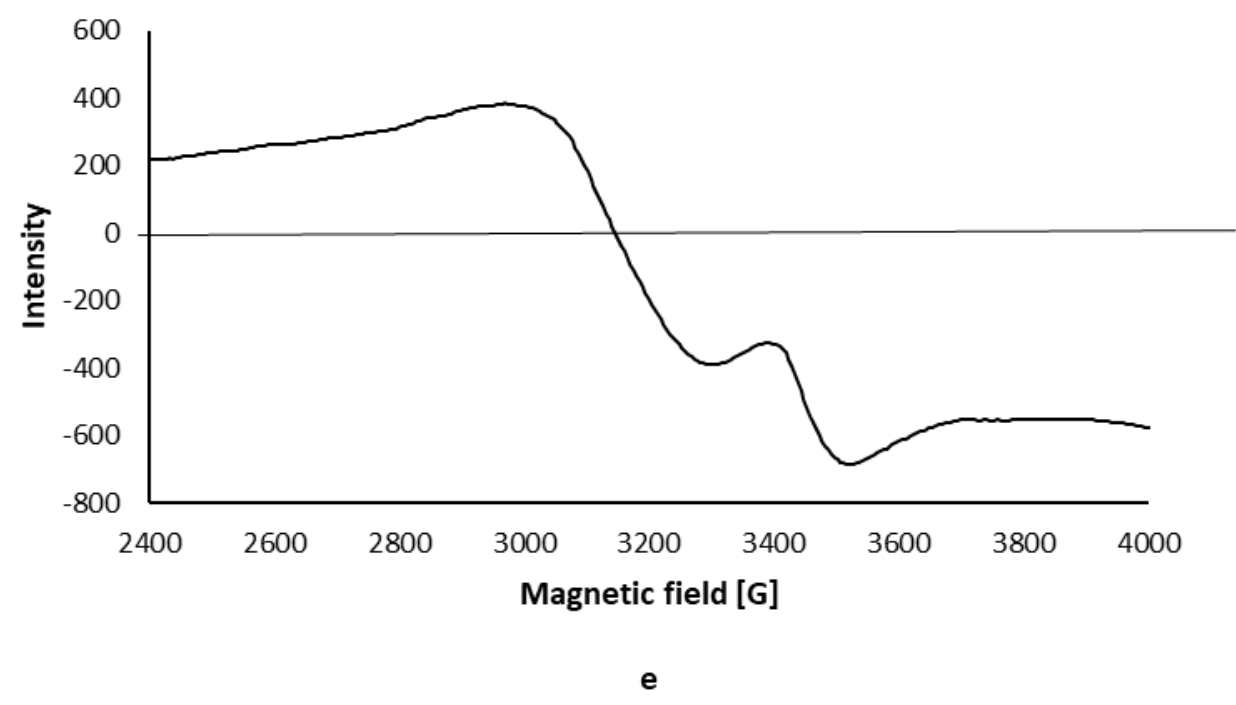

Figure 6. Electron Spin Resonance (ESR) spectra of deionized water saturated with nitrogen treated with GP for 5 (a), 15 (b), 30 (c), 60 (d) and 90 (e) $\mathrm{min}$.

\section{Conclusions}

Already elimination of dissolved oxygen and carbon dioxide from deionized water by blowing with the stream of nitrogen resulted in a higher ordering of the water macrostructure.

The subsequent treatment of the water with low-temperature glow plasma of low frequency (GP) produced aqueous clathrates with nitrogen guest molecules in various exited states depending on the treatment time. Based on the entropy criterion, the macrostructure formed on 30 and 5 min GP treatment is the most and least organized, respectively. The entropy of particular macrostructures was not linear against the GP treatment time. Independently of the applied GP treatment time the deal of the water molecules with asymmetrically stretched $\mathrm{O}-\mathrm{H}$ bonds declined and the decline was irregular against the treatment time. In terms of such selected physicochemical properties as mass, density, $\mathrm{pH}$, conductivity and surface tension saturated with nitrogen water treated with GP for 5 and $30 \mathrm{~min}$ distinctly differ from the samples treated for 15, 60 and $90 \mathrm{~min}$.

Author Contributions: J.C. run Raman spectra, K.C. run pH, conductivity measurements, W.C. run ESR spectra, K.K. run UV-VIS and Infrared Spectra, H.K. run Raman spectra, D.K. Thermogravimetry measurements, Z.O. equipped a research team in nanowater, P.T. invented the project, coordinated study and designed the text of this report, M.W. run surface tension and water density. All authors jointly participated in interpretation of all data and in writing report. All authors have read and agreed to the published version of the manuscript.

Funding: This research did not receive any specific grant from funding agencies in the public, commercial, or not-for-profit sectors.

Acknowledgments: Authors feel very much indebted to Jacek Soroka, DSc. of West-Pomeranian University of Technology in Szczecin (Poland) for his very substantial remarks and discussion of the subject.

Conflicts of Interest: No conflict of interest is known to the authors.

\section{References}

1. Chaplin, M.F. A proposal for the structuring of water. Biophys. Chem. 2000, 83, 211-221. [CrossRef]

2. Clary, D.C. Quantum dynamics in the smallest water droplet. Science 2016, 351, 1267-1268. [CrossRef] [PubMed]

3. Chaplin, M. Water Structure and Science. Available online: www.1.1sbu.ac.uk/water/water_vibrational_ spectrum.html (accessed on 12 December 2016).

4. Chen, Z.; Krasik, Y.E.; Cousens, S.; Ambujakshan, A.; Corr, C.; Dai, X.J. Generation of underwater discharges inside gas bubbles using a 30-needles-to-plate electrode. J. Appl. Phys. 2017, 122, 153303. [CrossRef] 
5. Hayashi, Y.; Takada, N.; Kanda, H.; Goto, M. Generation of pulsed discharge plasma in water with fine bubbles. Proc. APS Gaseous Conf. 2015, LW1, 123.

6. Khristolubova, V.I.; Kashapov, N.F.; Shaekhov, M.F. Gas and plasma dynamics of RF discharge jet of low-pressure in a vacuum chamber with flat electrodes and inside tube, Influence of RF discharge on the steel surface parameters. IOP Conf. Ser. Mater. Sci. Eng. 2016, 134, 012017. [CrossRef]

7. Muradia, S.; Nagatsu, M. Low-voltage pulsed plasma discharges inside water using a bubble self-generating parallel plate electrode with a porous ceramic. Appl. Phys. Lett. 2013, 102, 144105. [CrossRef]

8. Miichi, T.; Hayashi, N.; Ihara, S.; Satoh, S.; Yamade, C. Ozone generation inside bubbles in water. IEEJ Trans. Fund. Mater. 2001, 121, 448-452. [CrossRef]

9. Sato, K.; Yasuoka, K.; Ishii, S. Water Treatment with Pulsed Plasmas Generated Inside Bubbles. Ieej Trans. Fundam. Mater. 2008, 128, 401-406. [CrossRef]

10. Sharma, A.; Levko, D.; Raja, L.L.; Cha, M.S. Kinetics and dynamics of nanosecond streamer discharge in atmospheric-pressure gas bubble suspended in distilled water under saturated vapor pressure conditions. J. Phys. D: Appl. Phys. 2016, 49, 395205. [CrossRef]

11. Shang, K.; Li, J.; Wang, X.; Yao, D.; Lu, N.; Jiang, N.; Wu, Y. Evaluating the generation efficiency of hydrogen peroxide in water by pulsed discharge over water surface and underwater bubbling pulsed discharge. Jpn. J. Appl. Phys. 2015, 55, 01AB02. [CrossRef]

12. Sommers, B.; Foster, J. Plasma formation inside deformed gas bubbles submerged in water. In Proceedings of the American Physical Society, 65th Annual Gaseous Electronics Conference, Austin, TX, USA, 22-26 October 2012.

13. Takahashi, K.; Takeda, M.; Konno, R.; Takaki, K.; Satta, N. Influence of Electric Parameters on Hydroxyl Radical Production by Positive Pulsed Discharge Inside of a Bubble in Water. IEEE Trans. Plasma Sci. 2018, 47, 1105-1113. [CrossRef]

14. Takahashi, K.; Yagi, I.; Takaki, K.; Satta, N. Development of Pulsed Discharge Inside Bubble in Water. Ieee Trans. Plasma Sci. 2011, 39, 2654-2655. [CrossRef]

15. Verreycken, T.; Schram, D.C.; Leys, C.; Bruggeman, P.J. Spectroscopic study of an atmospheric pressure dc glow discharge with a water electrode in atomic and molecular gases. Plasma Sources Sci. Technol. 2010, 19, 45004. [CrossRef]

16. Yui, H.; Someya, Y.; Kusama, Y.; Kanno, K.; Banno, M. Atmospheric discharge plasma in aqueous solution: Importance of the generation of water vapor bubbles for plasma onset and physicochemical evolution. $J$. Appl. Phys. 2018, 124, 103301. [CrossRef]

17. Doughty, D.A.; Hartog, E.A.D.; Lawler, J.E. Current balance at the surface of a cold cathode. Phys. Rev. Lett. 1987, 58, 2668-2671. [CrossRef]

18. Iwabuchi, M.; Wada, K.; Takahashi, K.; Takaki, K.; Satta, N. Influence of Pulse Width on Decolorization Efficiency of Organic Dye by Discharge Inside Argon Bubble in Water. IEEJ Trans. Fundam. Mater. 2015, 135, 437-438. [CrossRef]

19. Liu, J.; He, B.; Chen, Q.; Li, J.; Xiong, Q.; Yue, G.; Zhang, X.; Yang, S.; Liu, H.; Liu, Q.H. Direct synthesis of hydrogen peroxide from plasma-water interactions. Sci. Rep. 2016, 6, 38454. [CrossRef]

20. Iwabuchi, M.; Takahashi, K.; Takaki, K.; Satta, N. Influence of sodium carbonate on decomposition of formic acid by pulsed discharge plasma inside bubble in water. Jpn. J. Appl. Phys. 2016, 55, 07LF02. [CrossRef]

21. Nemcova, L.; Nikiforov, A.; Leys, C.; Krcma, F. Chemical efficiency of $\{\mathrm{H}\} \_\{2\}\{\mathrm{O}\} \_\{2\}$ production and decomposition of organic compounds under action of DCC under water discharge in gas bubbles. IEEE Trans Plasma Sci. 2011, 39, 865-870. [CrossRef]

22. Pranevicius, L.; Tuckute, S.; Gedvilas, K. Water Vapor-Plasma-Enhanced Oxidation of Thin Titanium Films. Acta Phys. Pol. A 2013, 123, 907-910. [CrossRef]

23. Hagen, R. Plasma-Treated Water as a Superior Electrolyte. Available online: https://www. advancedsciencenews.com/plasma-treated-water-superior-electrolyte/ (accessed on 3 July 2017).

24. Białopiotrowicz, T.; Ciesielski, W.; Domański, J.; Doskocz, M.; Fiedorowicz, M.; Grąż, K.; Khachatryan, K.; Kołoczek, H.; Kozak, A.; Oszczęda, Z.; et al. Structure and physicochemical properties of water treated with low-temperature low-frequency plasma. Curr. Phys. Chem. 2016, 6, 312-320.

25. Lu, P.; Cullen, P.J.; Ostrikov, K. Atmospheric Pressure Nonthermal Plasma Sources. In Cold Plasma in Food and Agriculture; Elsevier BV: Amsterdam, The Netherlands, 2016; pp. 83-116. 
26. Bruggeman, P.J.; Kushner, M.J.; Locke, B.R.; E Gardeniers, J.G.; Graham, W.G.; Graves, D.B.; Hofman-Caris, R.C.H.M.; Marić, D.; Reid, J.P.; Ceriani, E.; et al. Plasma-liquid interactions: A review and roadmap. Plasma Sources Sci. Technol. 2016, 25, 53002. [CrossRef]

27. Bruggeman, P.J.; Iza, F.; Brandenburg, R. Foundations of atmospheric pressure non-equilibrium plasmas. Plasma Sources Sci. Technol. 2017, 26, 123002. [CrossRef]

28. Jaworska, M.; Oszczeda, Z.; Tomasik, P. Water treated with low-temperature, low-pressure, low-frequency glow plasma as a stimulant of pathogenicity and reproduction of biopesticides. Part I. Entomopathogenic fungi. Pol. J. Nat. Sci. 2018, 33, 561-568.

29. Murawski, M.; Schwarz, T.; Grygier, J.; Patkowski, K.; Oszczęda, Z.; Jelkin, I.; Kosiek, A.; Gruszecki, T.M.; Szymanowska, A.; Skrzypek, T.; et al. The utility of nanowater for ram semen cryopreservation. Exp. Boil. Med. 2014, 240, 611-617. [CrossRef]

30. Szymanowicz, J.; Schwartz, T.; Murawski, M.; Małopolska, M.; Oszczęda, Z.; Tuz, R.; Nowicki, J.; Bartkowski, P.M. Storage, of bear semen at $16-18^{\circ} \mathrm{C}$ in thew long term commercial extender prepared witg deionized water or nanowater. Anim. Reprod. 2019, 16, 1-7. [CrossRef]

31. Pater, A.; Zdaniewicz, M.; Satora, P.; Khachatryan, G.; Oszczęda, Z. Application of Water Treated with Low-Temperature Low-Pressure Glow Plasma for Quality Improvement of Barley and Malt. Biomolecules 2020, 10, 267. [CrossRef]

32. Pisulewska, E.; Ciesielski, W.; Jackowska, M.; Gąstoł, M.; Oszczęda, Z.; Tomasik, P.; Systems, B.N.N. Cultivation of Peppermint (Mentha Piperita Rubescens) Using Water Treated with Low-Pressure, Low-Temperature Glow Plasma of Low Frequency. Electron. J. Pol. Agric. Univ. 2018, 21, 1. [CrossRef]

33. Tomasik, P.; Oszczęda, Z. Applications of water treated with low-pressure, low- temperature glow plasma (nanowater) in food and cosmetic technology. Prom. Zdr. Ekol. 2019, 4, 21-28. (In Polish)

34. Tomasik, P. Essentials of Nanotechnology in Food Technology and Cosmetics; Sophia Scientific Editorial Board: Warsaw, Poland, 2019. (In Polish)

35. Oszczęda, Z.; Elkin, I.; Stręk, W. Equipment for Treatment of Water with Plasma. Polish Patent PL 216025 B1, 28 February 2014.

36. Reszke, E.; Yelkin, I.; Oszczęda, Z. Plasming Lamp with Power Supply. Polish Patent PL 227530 B1, 26 October 2017.

37. Federal Communications Commission, Interference Handbook. Available online: https://web.archive.org/ web/20131016064153/http://www.kyes.com/antenna/interference/tvibook (accessed on 11 March 2020).

38. Prahl, S. Optical Absorption of Water. Available online: http://omlc.ogi.edu/spectra/water/index.html2001 (accessed on 7 December 2017).

39. Vieitez, M.; Ivanov, T.I.; Ubachs, W.; Lewis, B.R.; De Lange, C. On the complexity of the absorption spectrum of molecular nitrogen. J. Mol. Liq. 2008, 141, 110-117. [CrossRef]

40. Tokushima, T.; Harada, Y.; Takahashi, O.; Senba, Y.; Ohashi, H.; Pettersson, L.G.M.; Nilsson, A.; Shin, S. High resolution $X$-ray emission spectroscopy of liquid water: The observation of two structural motifs. Chem. Phys. Lett. 2008, 460, 387-400. [CrossRef]

41. Engineering Tool Box. Available online: http://www.engineeringtoolboc.com/gases-solubility-water_1148. html (accessed on 20 January 2019).

42. Golde, M.F.; Thrush, B.A. Formation of excited states of N2 from ground state nitrogen atoms. Faraday Discuss. Chem. Soc. 1972, 53, 52. [CrossRef]

43. Kirillov, A.S. Electronically excited molecular nitrogen and molecular oxygen in the high-latitude upper atmosphere. Ann. Geophys. 2008, 26, 1159-1169. [CrossRef]

44. Ramya, K.R.; Venkathathan, A. Density functional theory study of oxygen clathrate hydrates. Indian J. Chem. 2013, 52A, 1063-1065.

(C) 2020 by the authors. Licensee MDPI, Basel, Switzerland. This article is an open access article distributed under the terms and conditions of the Creative Commons Attribution (CC BY) license (http://creativecommons.org/licenses/by/4.0/). 